\title{
Dynamic Contribution of Nestin-Expressing Stem Cells to Adult Neurogenesis
}

\author{
Diane C. Lagace, ${ }^{1}$ Mary C. Whitman, ${ }^{2}$ Michele A. Noonan, ${ }^{1}$ Jessica L. Ables, ${ }^{1}$ Nathan A. DeCarolis, ${ }^{1}$ Amy A. Arguello, ${ }^{1}$ \\ Michael H. Donovan, ${ }^{1}$ Stephanie J. Fischer, ${ }^{1}$ Laure A. Farnbauch, ${ }^{1}$ Robert D. Beech, ${ }^{3}$ Ralph J. DiLeone, ${ }^{3}$ \\ Charles A. Greer, ${ }^{2,4}$ Chitra D. Mandyam, ${ }^{5}$ and Amelia J. Eisch ${ }^{1}$ \\ ${ }^{1}$ Department of Psychiatry, University of Texas Southwestern Medical Center, Dallas, Texas 75390-9070, Departments of ${ }^{2}$ Neurobiology, ${ }^{3}$ Psychiatry, and \\ ${ }^{4}$ Neurosurgery, Yale University School of Medicine, New Haven, Connecticut 06520, and ${ }^{5}$ Committee on the Neurobiology of Addictive Disorders, The \\ Scripps Research Institute, La Jolla, California 92037
}

Understanding the fate of adult-generated neurons and the mechanisms that influence them requires consistent labeling and tracking of large numbers of stem cells. We generated a nestin-CreER ${ }^{\mathrm{T} 2} / \mathrm{R} 26 \mathrm{R}$-yellow fluorescent protein (YFP) mouse to inducibly label nestinexpressing stem cells and their progeny in the adult subventricular zone (SVZ) and subgranular zone (SGZ). Several findings show that the estrogen ligand tamoxifen (TAM) specifically induced recombination in stem cells and their progeny in nestin-CreER ${ }^{\mathrm{T} 2} / \mathrm{R} 26 \mathrm{R}-\mathrm{YFP}$ mice: 97\% of SGZ stem-like cells (GFAP/Sox2 with radial glial morphology) expressed YFP; YFP+ neurospheres could be generated in vitro after recombination in vivo, and maturing $\mathrm{YFP}+$ progeny were increasingly evident in the olfactory bulb (OB) and dentate gyrus (DG) granule cell layer. Revealing an unexpected regional dissimilarity in adult neurogenesis, YFP + cells accumulated up to $100 \mathrm{~d}$ after TAM in the OB, but in the SGZ, YFP + cells reached a plateau $30 \mathrm{~d}$ after TAM. In addition, most SVZ and SGZ YFP + cells became neurons, underscoring a link between nestin and neuronal fate. Finally, quantification of YFP + cells in nestin-CreER ${ }^{\mathrm{T} 2} / \mathrm{R} 26 \mathrm{R}-\mathrm{YFP}$ mice allowed us to estimate, for example, that stem cells and their progeny contribute to no more than $1 \%$ of the adult DG granule cell layer. In addition to revealing the dynamic contribution of nestin-expressing stem cells to adult neurogenesis, this work highlights the utility of the nestin-CreER ${ }^{\mathrm{T} 2} / \mathrm{R} 26 \mathrm{R}-\mathrm{YFP}$ mouse for inducible gene ablation in stem cells and their progeny in vivo in the two major regions of adult neurogenesis.

Key words: dentate gyrus; subgranular zone; subventricular zone; rostral migratory stream; olfactory bulb; tamoxifen

\section{Introduction}

In the postnatal brain, evidence suggests progeny of glial fibrillary acidic protein (GFAP)- and nestin-expressing stem cells become neurons and astrocytes by progression through distinct stages (Doetsch et al., 1999; Garcia et al., 2004; Kempermann et al., 2004; Ganat et al., 2006). In the subventricular zone (SVZ) and hippocampal subgranular zone (SGZ), the stage at which progeny are restricted to a neuronal fate is unknown. In addition, it is unclear in the adult how many of these cells integrate into the existing neural network. Studies addressing these questions typically use thymidine analogs such as bromdeoxyuridine (BrdU) that target rapidly dividing cells or transgenic reporter mice that label discrete stages of adult neurogenesis. In general, these techniques are of limited use for stem cell analysis because their markers either dilute with cell division or provide only transient label-

Received Aug. 21, 2007; revised Sept. 24, 2007; accepted Sept. 27, 2007

This work was supported by National Institutes of Health Grants DA016765 (A.J.E.), DC00210 and DC006972 (C.A.G.), DA07290 (N.A.D., M.A.N., and S.J.F.), DA16765-02S1 (A.A.A.), DA018017 (C.D.M.), and MH754572 (M.H.D.); Yale Medical Scientist Training Program Grant GM07205 (M.C.W.); and a postdoctoral research fellowship from the Canadian Institutes of Health Research (D.C.L.).

Correspondence should be addressed to Dr. Amelia J. Eisch, Department of Psychiatry, University of Texas Southwestern Medical Center, Dallas, TX 75390-9070. E-mail: amelia.eisch@utsouthwestern.edu.

DOI:10.1523/JNEUROSCI.3812-07.2007

Copyright $\odot 2007$ Society for Neuroscience $\quad$ 0270-6474/07/2712623-07\$15.00/0 ing (Yamaguchi et al., 2000; Dayer et al., 2003). Although viralmediated fluorescent labeling can tag stem cells and does not dilute, the necessity of intracranial injection and the restricted spread of virus make it nearly impossible for viruses to consistently label a large number of cells, particularly in the SGZ (van Praag et al., 2002). It is clear that questions of fate restriction and cellular contribution require a new approach to label and track large populations of stem cells and their progeny in the adult brain.

To address this challenge in studying neurogenesis, we and others created conditional and inducible nestin-driven transgenic mice (Beech et al., 2004; Yu et al., 2005; Carlen et al., 2006; Imayoshi et al., 2006; Kuo et al., 2006; Burns et al., 2007). Whereas many of these mouse models are highly effective in labeling and tracking the multipotent lineage of nestinrecombined cells in the embryo, only three of these models have demonstrated efficient labeling within the adult SVZ (Yu et al., 2005; Carlen et al., 2006; Burns et al., 2007), and none have labeled the large pool of adult SGZ stem and progenitor cells.

Here we report the first inducible nestin-CreER ${ }^{\mathrm{T} 2}$ mouse that can be used to label, track, and phenotype stem cells and their progeny in the adult SVZ and SGZ. Using this mouse, we explore whether adult-generated neurons are derived from the nestin lineage. In addition, we quantify the diverse composition of la- 
beled cells over months following recombination, as well as estimate the total contribution of stem cells and their progeny to adult mice. Our data provide unique insight into the importance of stem cells to neurogenesis in the SVZ and SGZ and underscore the utility of this mouse in gene deletion from stem cells and their progeny in the adult brain.

\section{Materials and Methods}

Generation and genotyping of nestin-CreER $R^{T 2} / R 26 R$-yellow fluorescent protein transgenic mice. Animal experiments were performed in accordance with the Guide for the Care and Use of Laboratory Animals and approved by the University of Texas Southwestern Animal Care and Use Committee. The CreER ${ }^{\mathrm{T} 2}$ sequence (Indra et al., 1999) (generous gift from P. Chambon, Institute for Genetics and Cellular and Molecular Biology, Strasbourg, France) was cloned into the SalI and NheI sites of Nestin Xh5 plasmid (generous gift from W. Zhong, Yale University, New Haven, CT). The Xh5 plasmid has been published previously in other mouse models and contains similar elements to Nes/PlacZ/3 introns (Zimmerman et al., 1994; Beech et al., 2004). The nestin-CreER ${ }^{\mathrm{T} 2}$ founder mice were generated by pronuclear injection of SmaI digest of nestin-CreER ${ }^{\mathrm{T} 2}$ into $\mathrm{C} 57 \mathrm{Bl} / 6 \mathrm{~J}$ fertilized eggs. Five independent lines were generated $(g, h, i, j, k)$, with four lines $(g, i, j, k)$ having robust Cre mRNA in brain as determined by quantitative reverse transcription-PCR (data not shown). Nestin-CreER ${ }^{\mathrm{T} 2}$ mice were bred with R26R yellow fluorescent protein (YFP) reporter mice, resulting in bigenic mice heterozygous for both transgenes (see Fig. 1a). Mice were genotyped by PCR using genomic DNA and primers previously published for Cre (Indra et al., 1999) and R26R reporter (Soriano, 1999) mice.

Tamoxifen and BrdU administration. Nestin-CreER ${ }^{\mathrm{T} 2} / \mathrm{R} 26 \mathrm{R}-\mathrm{YFP}$ mice (5-7 weeks old) were administered tamoxifen (TAM) at $180 \mathrm{mg} / \mathrm{kg} / \mathrm{d}$ for $5 \mathrm{~d}$ (intraperitoneally; dissolved in 10\% EtOH/90\% sunflower oil). This dosage was based on preliminary studies with hydroxytamoxifen (up to 1 $\mathrm{mg} / \mathrm{d}$ for $5 \mathrm{~d}$ ) and TAM (up to $300 \mathrm{mg} / \mathrm{kg} / \mathrm{d}$ for $10 \mathrm{~d}$ ) that demonstrated $5 \mathrm{~d}$ of $180 \mathrm{mg} / \mathrm{kg} / \mathrm{d}$ TAM produced the maximal recombination with minimal lethality $(<5 \%)$. To examine the impact of TAM on survival of adult-generated neurons, mice were given BrdU (150 mg/kg, i.p.) $1 \mathrm{~d}$ before TAM and killed $28 \mathrm{~d}$ later. For phenotypic analysis, mice were killed $1 \mathrm{~d}(n=7), 12 \mathrm{~d}(n=11), 30 \mathrm{~d}(n=10), 65 \mathrm{~d}(n=9)$, and $100 \mathrm{~d}$ $(n=6)$ after TAM.

Immunohistochemistry. Mice were anesthetized and perfused transcardially with cold $4 \%$ paraformaldehyde in $0.1 \mathrm{M}$ PBS. Brains were removed from the skull, postfixed in $4 \%$ paraformaldehyde overnight, and transferred to $30 \%$ sucrose in $0.1 \mathrm{M}$ PBS. Brains were sectioned 30 or $40 \mu \mathrm{m}$ thick on a freezing microtome in either the coronal or sagittal plane. Sections were stored in $1 \times$ PBS with $0.01 \%$ sodium azide (Donovan et al., 2006). All immunohistochemistry (IHC) was completed on tissue mounted onto charged slides as published previously (Mandyam et al., 2004, 2007), with the exception that Sox2/GFAP staining was performed using free-floating IHC.

The following primary antibodies were used: rat monoclonal antiBrdU (catalog \#OBT0030, 1:300; Accurate, Westbury, NY); mouse monoclonal anti-calretinin (CR; catalog \#6B3, 1:1000; Swant, Bellinzona, Switzerland); goat polyclonal anti-doublecortin (DCX; catalog \#sc-8066, 1:1000 or 1:5000; Santa Cruz Biotechnology, Santa Cruz, CA); mouse anti-GAD 65-67 (catalog \#MSA-225, 1:1000; Stressgen, Victoria, British Columbia, Canada); mouse anti-CR (catalog \#MAB1568, 1:1000; Chemicon, Temecula, CA); mouse monoclonal anti-GFAP (catalog \#MAB360, 1:3000; Chemicon); rabbit polyclonal anti-green fluorescent protein (catalog \#A11122, 1:500 or 1:3000; Invitrogen, Eugene, OR); rabbit polyclonal anti-Ki67 (catalog \#NCL-Ki67p, 1:500; Novocastra Laboratories, Norwell, MA); rabbit anti-SRY-related HMG-box gene 2 (Sox2; catalog \#AB5603, 1:3000; Chemicon); mouse anti-nestin (catalog \#60051A, 1:2000; BD Pharmingen, San Jose, CA).

To quench endogenous lipofuscin fluorescence, some sections [olfactory bulb (OB) sections for DCX/YFP] were stained with $1 \%$ Sudan Black in $70 \%$ methanol for $5 \mathrm{~min}$, cleared in 70\% ethanol, rinsed in PBS, and mounted. Antigen retrieval on slide-mounted sections was performed using $0.01 \mathrm{M}$ citric acid, $\mathrm{pH} 6.0$, at $100^{\circ} \mathrm{C}$ for $15 \mathrm{~min}$, followed by $10 \mathrm{~min}$ in PBS at room temperature. To remove any endogenous peroxidase activity, all sections were incubated with $0.3 \% \mathrm{H}_{2} \mathrm{O}_{2}$ for $30 \mathrm{~min}$. Nonspecific binding was blocked with $2-3 \%$ serum (donkey, horse, or bovine serum albumin) and $0.3 \%$ Triton X-100 in PBS for 30-60 min. Antibody specificity was determined by lack of staining after omission of primary or secondary antibodies.

Incubation with the primary antibody was done with 3\% serum and $0.3 \%$ Tween 20 overnight. For double or triple labeling, some primary antibodies were simultaneously incubated (DCX/CR/YFP; Sox2/GFAP; nestin/YFP; GAD65-67/YFP). For Ki67/YFP IHC, incubation with each antibody was done separately. Slides were first incubated with the YFP antibody, and staining was completed, followed by fixation of the stained slides in 4\% paraformaldehyde for 20-60 min, before incubation with the primary antibody for Ki67. Similarly, for Sox2/GFAP/YFP IHC, slides were stained for both the Sox 2 and GFAP simultaneously, and the stained slides were fixed in $4 \%$ paraformaldehyde for 20-60 min before staining for YFP.

For single labeling of YFP, primary antibody incubation was followed by labeling with a biotin-tagged donkey anti-rabbit secondary antibody with 1.5\% serum for $1 \mathrm{~h}$ (catalog \#711-065-152, 1:200; Jackson ImmunoResearch, West Grove, PA). Sections were then incubated in $\mathrm{ABC}$ for $1 \mathrm{~h}$ (catalog \#PK-6100, 1:50; Vector Laboratories, Burlingame, CA), and staining was visualized with Tyramide-Plus signal amplification (catalog \#SAT705A, 1:50; PerkinElmer Life Sciences, Boston MA). For DCX IHC in the $\mathrm{OB}$, primary antibody incubation was followed by incubation for up to $4 \mathrm{~h}$ with an Alexa-conjugated secondary antibody (1:1000; Invitrogen, Carlsbad, CA). For CR, Sox2, and GFAP staining, primary antibody incubation was followed by incubation for up to $4 \mathrm{~h}$ with a fluorescenttagged secondary antibody [Cy2-, Cy3-, or Cy5-conjugated IgG antibodies (catalog \#715-225-150, 711-165-152, 711-065-152; 1:200; Jackson ImmunoResearch)]. Alternatively, for YFP, DCX, Ki67, and nestin staining in the SGZ, primary antibody incubation was followed with an appropriate biotin-tagged secondary, followed by $\mathrm{ABC}$ and tyramide signal amplification.

All slides were counterstained with a nuclear counterstain, DAPI $\left(4^{\prime}, 6-\right.$ diamidine-2' -phenylindole dihydrochloride; catalog \#236276, 1:5000; Roche Applied Science, Indianapolis, IN), red Nissl (catalog \#N-21482, 1:200; Invitrogen), or DRAQ5 (catalog \#BOS-889-001, 1:1000; Alexis Biochemicals, San Diego, CA). All slides were dehydrated and coverslipped using DPX.

Microscopic analysis and quantification. Quantification of cell number within the hippocampus was performed at $630 \times$ using an Olympus (Tokyo, Japan) BX-51 microscope by an observer blind to experimental groups. Slides were coded during IHC, and the code was not broken until after analysis was complete. For analysis in the hippocampus, YFP+ cells were quantified in every ninth coronal section throughout the SGZ and outer portion of the granule cell layer (GCL) of the dentate gyrus (bregma, -0.82 to $-4.24 \mathrm{~mm}$ ) as described previously (Mandyam et al., 2007).

The number of YFP+ cells per OB glomerulus was quantified as reported previously (Merson et al., 2006). Briefly, YFP+ cells were counted in 50 glomeruli per mouse in five matched serial sections of the mouse OB [10 glomeruli per section; glomeruli chosen as described by Merson et al. (2006)]. The average number of YFP + cells per glomerulus is reported. For analysis of the number of YFP+ cells in the OB GCL, four matched serial OB sections were analyzed. YFP + cells in the OB $1 \mathrm{~d}$ after TAM were not quantified because of the very low number. The volume of the OB GCL excluding the rostral migratory stream (RMS) was obtained via optical fractionation using Stereoinvestigator software (MBF Bioscience, Williston, VT). A grid $\left(500 \times 500 \mu \mathrm{m}^{2}\right)$ was superimposed over each section, and YFP + cells were counted at $400 \times$ in $50 \times 50 \times 6 \mu \mathrm{m}^{3}$ sample volumes with an upper and lower guard distance of $1 \mu \mathrm{m}$.

Phenotypic analysis of YFP + cells (50-150 cells per mouse for the OB and SGZ, $n=4-6$ mice per time point; $100-600$ cells per mouse for the RMS and GCL, $n=2-3$ mice per time point) was performed using a confocal microscope [Leica (Bannockburn, IL) TCS SL confocal and Zeiss (Thornwood, NY) Axiovert 200 and LSM510-META; emission wavelengths of 488,543 , and 633 ; magnification of $630 \times$ to $1000 \times$ ]. Scanning and optical sectioning in the $Z$ plane was performed as de- 

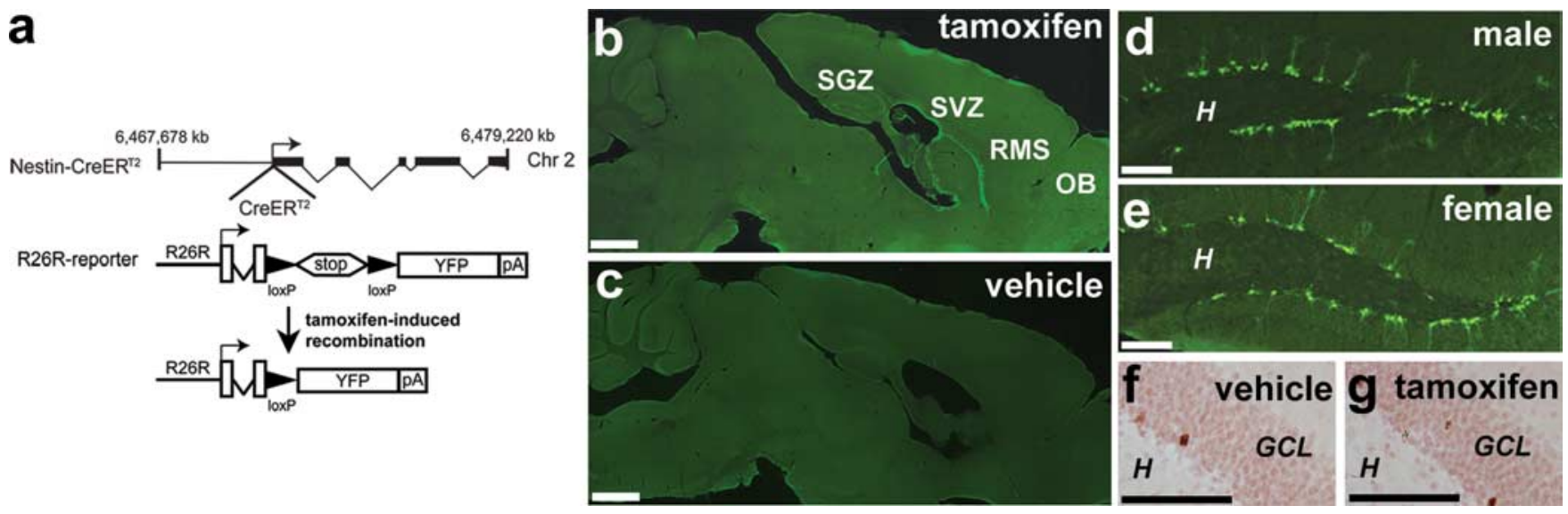

Figure 1. Recombination in nestin-CreER ${ }^{T 2} / R 26 R-Y F P$ mice is induced by TAM and is specific to neurogenic regions. $\boldsymbol{a}$, The nestin-CreER ${ }^{\mathrm{T} 2}$ construct has $5.8 \mathrm{~kb}$ of the nestin promoter and exons $1-3$, including the second intronic enhancer. $\boldsymbol{b}, \boldsymbol{c}$, YFP + cells are evident $12 \mathrm{~d}$ after TAM in the SVZ, RMS, OB GCL, and SGZ of nestin-CreER 2 /R26R-YFP mice given TAM but not vehicle. $\boldsymbol{d}$, $\boldsymbol{e}$, Recombination efficiency in the SGZ is similar in male and female mice $12 \mathrm{~d}$ after TAM (male, $3654 \pm 278 \mathrm{vs}$ female, $4239 \pm 414$ ). $\boldsymbol{f}, \boldsymbol{g}$, Mice given BrdU $1 \mathrm{~d}$ before TAM or vehicle and killed $28 \mathrm{~d}$ later have similar numbers of SGZ BrdU cells (vehicle, $2718 \pm 278$ vs TAM, $2788 \pm 238$ ). Scale bars: $\boldsymbol{b}, \boldsymbol{c}, 1 \mathrm{~mm} ; \boldsymbol{d}-\boldsymbol{g}, 100 \mu \mathrm{m}$. H, Hilus of dentate gyrus.

scribed previously (Mandyam et al., 2004, 2007), and fluorescently labeled confocal images presented here were taken from one optical slice and imported into Photoshop (Adobe Systems, San Jose, CA) for composition purposes or into MetaMorph for RMS and OB GCL phenotypic analysis. Verification of colocalization in the OB and SGZ was achieved by importing stacks of $Z$ images into a three-dimensional (3D) reconstruction program, Volocity (Improvision, Waltham, MA), and performing rotation, transient modification, and $3 \mathrm{D}$ rendering.

Statistical analyses. The data are reported as mean \pm SEM. Statistical analyses were performed using a multiple variable ANOVA followed by a Bonferroni post hoc test. All statistical analyses were performed using either SPSS (Chicago, IL; version 11.0.2) or Prism (version 4.0) software. Statistical significance was defined as $p<0.05$.

\section{Results}

Nestin-CreER ${ }^{\mathrm{T} 2} /$ R26R-YFP mice display TAM-induced recombination in neurogenic brain regions

The nestin-CreER ${ }^{\mathrm{T} 2}$-inducible transgenic mouse was generated using $5.8 \mathrm{~kb}$ of the nestin promoter and exons $1-3$ of the nestin gene. Recombination efficacy was tested by administering TAM to nestin-CreER ${ }^{\mathrm{T} 2} / \mathrm{R} 26 \mathrm{R}-\mathrm{YFP}$ mice. TAM binds to the mutated estrogen receptor $\left(\mathrm{ER}^{\mathrm{T} 2}\right)$ allowing $\mathrm{Cre}-\mathrm{ER}^{\mathrm{T} 2}$ to translocate into the nucleus and excise the STOP codon, allowing for subsequent YFP expression (Fig. 1a). Adult mice from four founder lines $(g, i, j, k)$ had YFP + cells in the SVZ, RMS, and OB, whereas two founder lines $(i, k)$ had YFP + cells additionally in the SGZ (Fig. 1b). Data presented here are from the $k$ line. In all lines, there was no appreciable number of YFP + cells in non-neurogenic regions, such as the cortex, thalamus, and cerebellum. Also, no line had Cre-induced abnormalities, contrary to previous reports (Forni et al., 2006). At all time points examined, no YFP + cells were detectable in nestin-CreER ${ }^{\mathrm{T} 2} / \mathrm{R} 26 \mathrm{R}-\mathrm{YFP}$ mice in the absence of TAM (Fig. 1c). The YFP + cell number was also similar between male and female mice (e.g., $12 \mathrm{~d}$ after TAM: number of YFP + cells in SGZ in male, $3654 \pm 278$ vs female, $4239 \pm 414$ ) (Fig. 1d,e). TAM did not alter the survival of adult-generated cells, as demonstrated by quantification of the number of surviving BrdU-labeled cells (e.g., $28 \mathrm{~d}$ after BrdU injection: number of BrdU + cells in SGZ in vehicle, $2718 \pm 278$ vs TAM, $2788 \pm$ 238) (Fig. 1f,g). Together, these data suggest that the nestin$\mathrm{CreER}^{\mathrm{T} 2}$ system targets adult stem cells and their progeny in the well characterized regions of adult neurogenesis.
Recombination in stem cells and their progeny in the SVZ results in an increasing number of newly formed mature neurons in the RMS and $O B$

The time course of the appearance of recombined (YFP+) cells in the SVZ, and subsequently in the OB GCL and glomerular cell layer (GL), revealed a dynamic addition of new cells in the adult (Fig. $2 a-c$ ). One day after TAM, nestin-lineage (YFP +) cells were evident in the SVZ, with few in the RMS and none in the OB (Fig. $2 a)$. In agreement with recombination taking place in stem/progenitor cells, YFP + cells were evident in the SVZ at all time points examined (Fig. 2a), and YFP+ neurospheres could be propagated in vitro from the SVZ of nestin-CreER ${ }^{\mathrm{T} 2} / \mathrm{R} 26 \mathrm{R}-\mathrm{YFP}$ mice given TAM in vivo (supplemental Fig. $1 a-d$, available at www. jneurosci.org as supplemental material). Both the OB GCL and OB GL showed an accumulation of YFP+ cells through $100 \mathrm{~d}$ after TAM (Fig. $2 b, c)$ (GCL: $F_{(4,24)}=11.9, p<0.0001 ;$ GL: $F_{(3,25)}$ $=12.2, p<0.005)$. The vast majority of YFP + cells were in the OB GCL rather than in the GL (note difference in $y$-axis in Fig. 2, $b$ vs $c$ ). Within the OB GCL, YFP+ cells were most dense in the deep internal portions of the GCL throughout the longitudinal axis of the $\mathrm{OB}$, consistent with previous reports in adult mice using BrdU to assess OB neurogenesis (Lemasson et al., 2005; Mandairon et al., 2006). Our quantification allowed estimation of the contribution of YFP + cells to adult OB. Because the adult mouse OB GCL has $\sim 410,000$ cells $/ \mathrm{mm}^{3}$ (Parrish-Aungst et al., 2007), YFP+ cells represented $0.3,1.1$, and $2.6 \%$ of the total OB GCL density at 30,65, and $100 \mathrm{~d}$ after TAM, respectively. In contrast, because each glomerulus is estimated to be surrounded by $\sim 100$ periglomerular cells [data not shown and Merson et al. (2006)], YFP + cells represented 2.7, 3.1, and 4.9\% of total periglomerular cell number at 30, 65, and $100 \mathrm{~d}$ after TAM, respectively.

Consistent with the significant increase in YFP + cells over time, phenotypic analysis revealed increasing maturity of YFP+ cells in the RMS/OB. There was a significant difference in the percentage of neuroblasts recombined [YFP +/DCX + (Brown et al., 2003)] at increasing times after TAM (Fig. $2 d)\left(F_{(2,14)}=6.1\right.$; $p<0.05)$, as well as among the caudal RMS, RMS in OB, and OB GCL (Fig. $2 d)\left(F_{(2,14)}=28.3 ; p<0.0001\right)$. Over time, in the caudal RMS, the percentage of YFP + cells that were neuroblasts increased, whereas in the OB, the percentage of YFP + cells that 

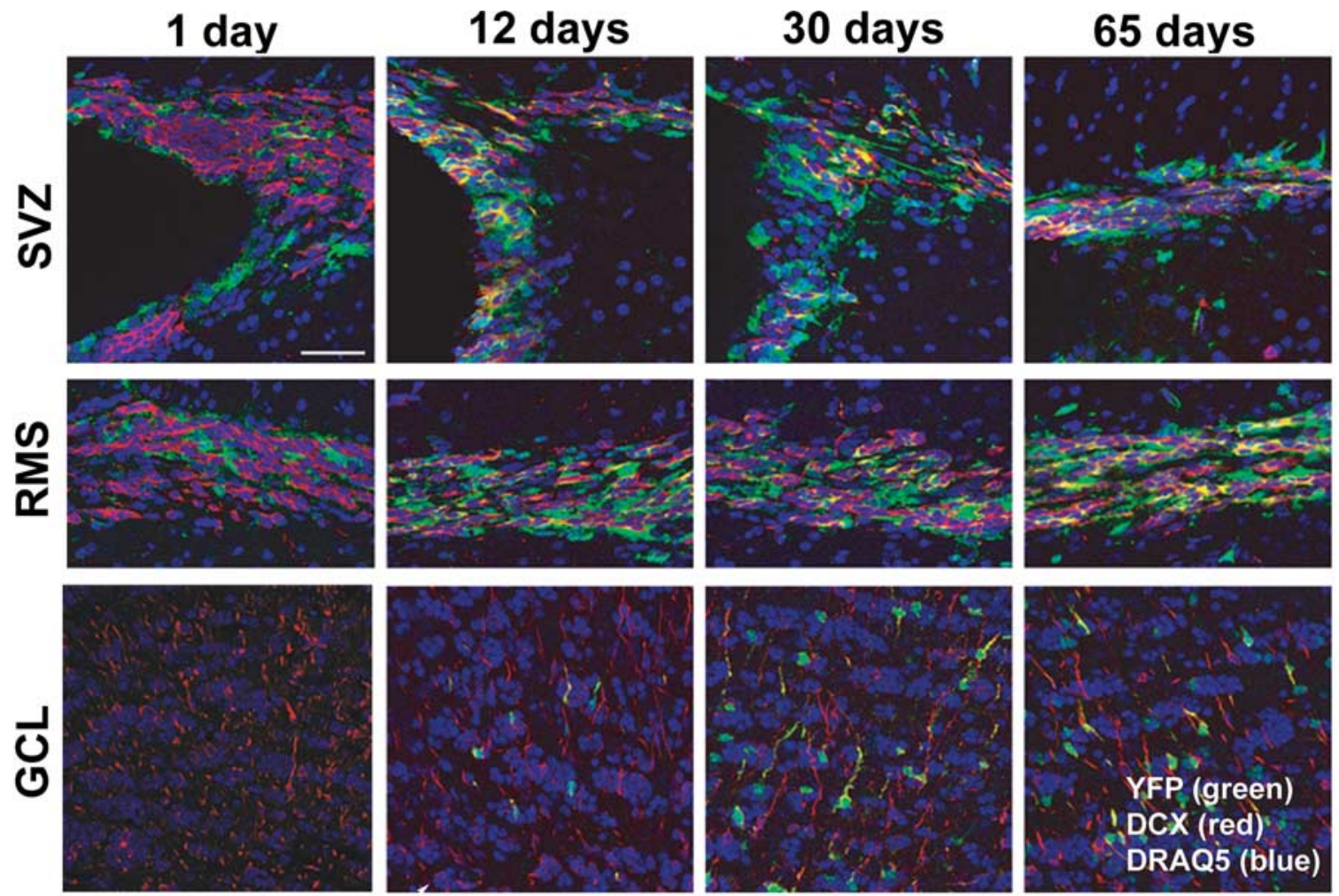
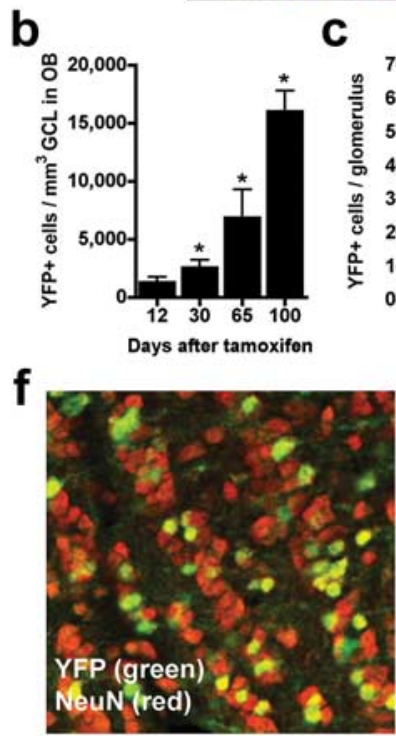

C

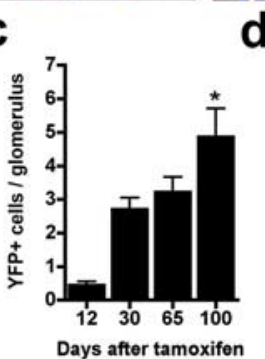

g

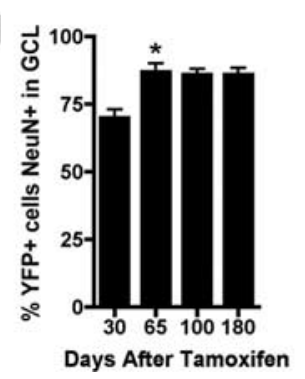

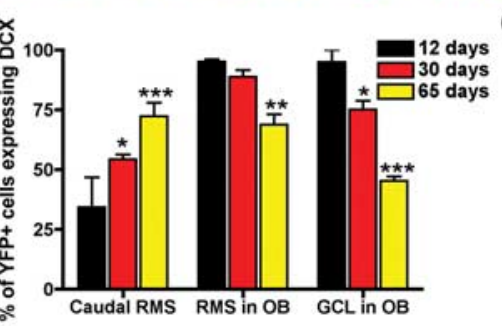

h

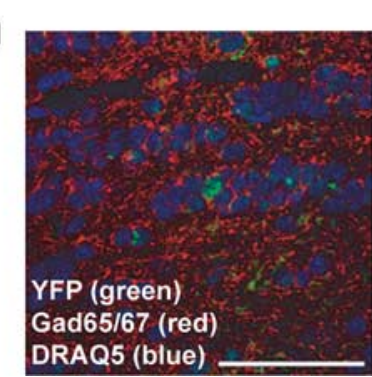

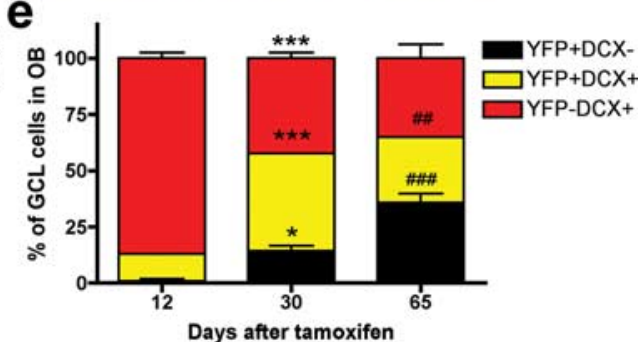

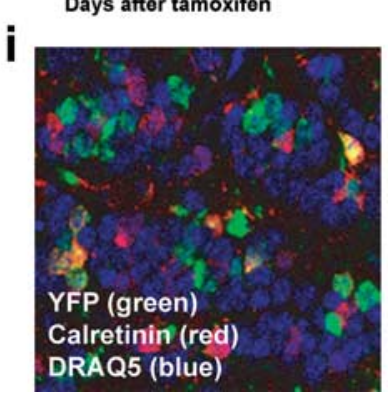

Figure 2. Neurogenesis in the SVZ/RMS/OB following TAM. $\boldsymbol{a}$, Time course for the appearance of YFP + cells in the SVZ, RMS, and OB GCL 1, 12, 30, and 65 d after TAM. Recombined cells (YFP +, green) are present $1 \mathrm{~d}$ after TAM within the SVZ, whereas fewer YFP + cells are present in the RMS and virtually no recombined cells are present within the GCL. With increasing time after TAM, there are many recombined cells in each of these areas with a variable proportion of these cells being neuroblasts as demonstrated by coexpression of YFP and DCX (red). $\boldsymbol{b}, \boldsymbol{c}, \mathrm{YFP}+$ cells in the OB GCL (a) and OB GL (b) significantly increased up to $100 \mathrm{~d}\left({ }^{*} p<0.05\right.$ vs $12 \mathrm{~d}$ ). $\boldsymbol{d}$, The proportion of YFP + cells that are migrating neuroblasts $(\mathrm{DCX}+)$ increased in the caudal RMS but decreased in the RMS in $\mathrm{OB}$ and $\mathrm{GCL}$ in $\mathrm{OB}\left({ }^{*} p<0.05,{ }^{* *} p<0.01\right.$, and ${ }^{* * *} p<0.005 \mathrm{vs} 12 \mathrm{~d}$ ). $e$, The proportion of YFP + cells (black and yellow bars) that are not migrating neuroblasts (black bars) increased in the $0 \mathrm{~B}$ $\mathrm{GCL}\left({ }^{*} p<0.05\right.$ and ${ }^{* * * *} p<0.005$ vs $12 \mathrm{~d} ;{ }^{\# \#} p<0.01$ and ${ }^{\# \# \#} p<0.005$ vs $\left.30 \mathrm{~d}\right) . \boldsymbol{f}-\boldsymbol{i}$, Thirty days after TAM, most recombined cells $(\boldsymbol{f}, \boldsymbol{g})$ in the GCL were NeuN $+\left({ }^{*} p<0.05\right.$ vs $\left.30 \mathrm{~d}\right)$ as well as GABAergic interneurons $(\boldsymbol{h}, \boldsymbol{i})$, as assessed via colabeling with YFP and GAD65/67 ( $\boldsymbol{h}$; counterstain DRAQ5) and CR (i). Scale bar: $\boldsymbol{f}, \boldsymbol{h}, \boldsymbol{i}, 50 \mu \mathrm{m}$. Error bars indicate SEM.

were neuroblasts decreased. This correlates with the significant increase in the percentage of YFP + cells in the GCL that did not express DCX between 12 and $30 \mathrm{~d}$ or between 30 and $65 \mathrm{~d}$ (Fig. 2e) (phenotype by time interaction: $F_{(4,18)}=70.8 ; p<0.0001$ ). These changes are expected because of the differentiation of YFP + cells and their progeny. Indeed, $>75 \%$ of YFP + cells in the OB GCL expressed the mature neuronal marker $\mathrm{NeuN}$ at 65 and $100 \mathrm{~d}$ after TAM (Fig. 2f,g) $\left(F_{(2,11)}=10.8 ; p<0.005\right)$, in agreement with BrdU survival studies demonstrating $\sim 80 \%$ of OB GCL BrdU+ cells label with NeuN (Mandairon et al., 2006). As expected (Lois and AlvarezBuylla, 1994), many YFP+ OB GCL cells were also GABAergic (Fig. $2 h$ ), and a proportion were also CR+ (Fig. 2i).

Recombination in stem cells and their progeny in the SGZ results in an increasing number of newly formed mature neurons in the hippocampal GCL

At all time points after TAM, YFP + cells were prominent within the dentate gyrus, with $>90 \%$ of cells residing within the SGZ 
a

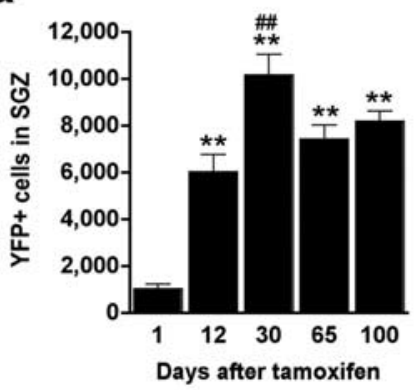

b

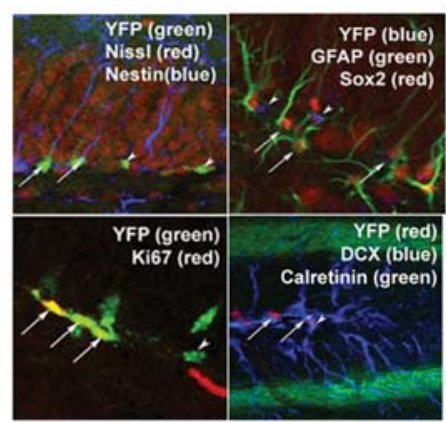

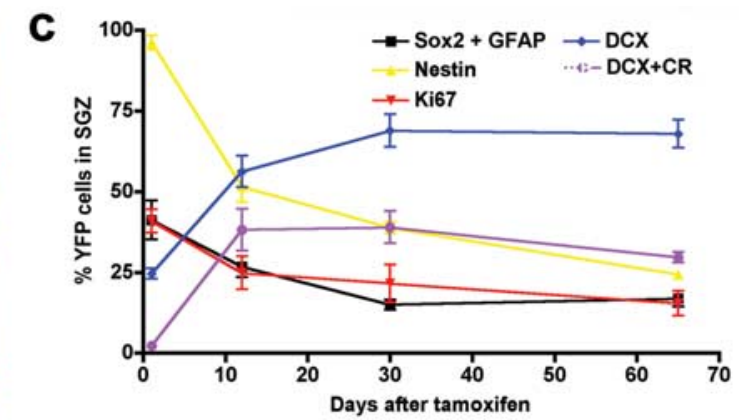

d

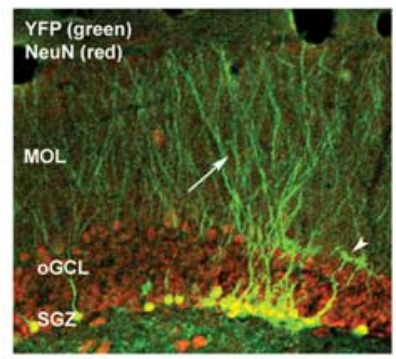

e

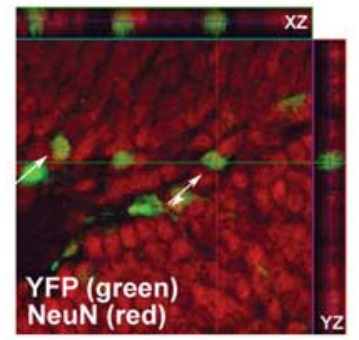

$f$

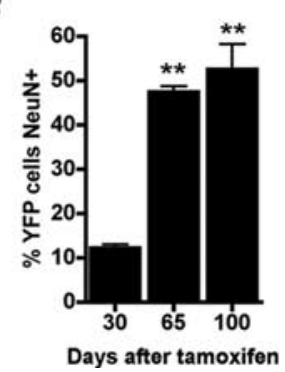

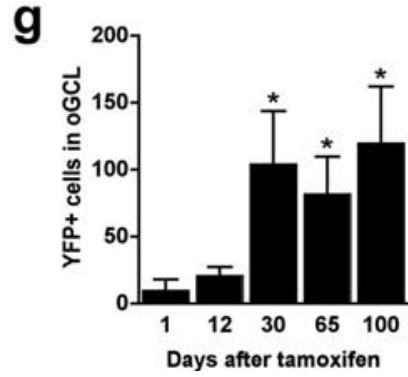

Figure 3. Neurogenesis in the SGZ after TAM. $\boldsymbol{a}$, At increasing time points after TAM, the YFP + cell number in the hippocampal SGZ increased up to $30 \mathrm{~d}\left({ }^{* *} p<0.01 \mathrm{vs} 1 \mathrm{~d}\right.$; $\left.{ }^{\# \#} p<0.01 \mathrm{vs} 12 \mathrm{~d}\right)$. $\boldsymbol{b}, \boldsymbol{c}$, The proportion of YFP + cells in SGZ-expressing immature markers decreased, whereas those expressing mature markers increased (arrows indicate YFP $+/ \mathrm{Nestin}+$, YFP $+/ \mathrm{GFAP}+/ \mathrm{Sox} 2+$, $\mathrm{YFP}+/ \mathrm{Ki} 67+$, and YFP +/DCX +/CR+; arrowheads indicate YFP +/Nestin - and YFP +/GFAP - /Sox2 + ). $\boldsymbol{d}-\boldsymbol{f}$, An increasing percentage of YFP + cells in the GCL of the dentate gyrus has a mature phenotype with branched processes (d, arrow) extending into the molecular layer and colocalization with the neuronal marker NeuN $\left({ }^{* *} p<0.01\right.$ vs $30 \mathrm{~d}$; ${ }^{\# \#} p<0.01$ vs $\left.65 \mathrm{~d}\right)(\boldsymbol{e}$; arrows indicate YFP +/NeuN +). $\boldsymbol{g}$, The YFP + cell number in the oGCL increased ( ${ }^{*} p<0.01$ vs $12 \mathrm{~d}$ ). Error bars indicate SEM.

relative to the other dentate gyrus regions (Fig. 1d,e). There was a significant difference in the number of SGZ YFP+ cells at increasing times after TAM, with significantly more cells between $1 \mathrm{~d}$ and all other time points, as well as between 12 and $30 \mathrm{~d}$ (Fig. $3 a)\left(F_{(4,42)}=15.5 ; p<0.005\right)$. There was no significant change between 30-65 $\mathrm{d}$ and 65-100 d after TAM, indicating that the number of YFP + cells reaches a plateau at $30 \mathrm{~d}$. Because the adult mouse has $\sim 1$ million dentate gyrus GCL cells (Abusaad et al., 1999; Harburg et al., 2007), YFP+ cells are estimated to represent $1.0,0.75$, and $0.82 \%$ of the total dentate gyrus GCL cells 30,65 , and $100 \mathrm{~d}$ after TAM, respectively. The plateau in the SGZ is likely not attributable to inefficient labeling, because at $12 \mathrm{~d}$ after TAM, $97.1 \pm 1.6 \%$ of stem-like SGZ cells were recombined. In this analysis, stem-like cells were identified by their immunoreactivity for both Sox 2 (which labels astrocyte stem-like cells, rapidly dividing precursor cells, and mature astroglial cells) and GFAP (which labels astrocyte stem-like cells and mature astroglial cells) in combination with assessment for stem-like radial glial morphology using confocal analysis (Seri et al., 2001; Graham et al., 2003; Pevny and Rao, 2003; Komitova and Eriksson, 2004; Seri et al., 2004; Hattiangady and Shetty, 2007). Moreover, this plateau was not likely caused by TAM- or YFP-induced disruption of gross cellular function, because a neurogenic stimulus, such as free access to a running wheel, significantly increased the number of YFP+ SGZ cells (supplemental Fig. $2 a-c$, available at www.jneurosci.org as supplemental material) (bregma by treatment interaction: $\left.F_{(11,110)}=2.647 ; p<0.01\right)$. This suggests that at least some of the recombined progenitor cells or their progeny can respond to a neurogenic stimulus. Considering mice were placed on the running wheels at a time point when YFP + cells present diverse cellular phenotypes (Fig. $3 c$ ), the relatively modest effect of running in our data compared with others likely results from the specific sensitivity of type 2 cells to this neurogenic stimulus (Kronenberg et al., 2003).
As would be expected if labeling SGZ stem cells and their progeny, nestin-lineage YFP + cells were morphologically heterogeneous after TAM (Figs. 1d,e, 3b,c). Using IHC, morphological analyses, and confocal microscopy, we classified YFP + cells into nonexclusive phenotypic categories: stem-like (Sox2+/GFAP+), stem/progenitor (nestin + ), dividing $(\mathrm{Ki} 67+)$, immature neurons $(\mathrm{DCX}+)$, or postmitotic neurons $(\mathrm{DCX}+/ \mathrm{CR}+)($ Fig. 3b,c) (Kempermann et al., 2004; Ming and Song, 2005; Hattiangady and Shetty, 2007). There was a significant difference in the proportion of recombined cells in these categories $\left(F_{(4,60)}=53.18\right.$; $p<0.000)$ that changed after TAM $\left(F_{(3,60)}=5.87 ; p<0.005\right)$ (Fig. $3 c$ ). Between 1 and $12 \mathrm{~d}$, YFP + cells matured from being dividing, stem-like, and/or progenitor cells into immature or postmitotic neurons (Fig. 3b,c). In contrast, between 12-30 and $30-65 \mathrm{~d}$, the proportion of YFP + cells that expressed the different phenotypes remained constant ( post hoc $>0.05$ ). Together, these data suggest that nestin drives expression in stem-like and progenitor cells in the SGZ. This is supported by the presence of stem-like recombined cells with radial glial morphology in the SGZ at all time points, including $100 \mathrm{~d}$ after TAM.

Over time, labeled stem cells and their progeny gave rise to mature dentate gyrus GCL neurons. At $30 \mathrm{~d}$ and beyond, the majority of the YFP + SGZ cells displayed a long process extending up into molecular layer capped by a highly arborized dendritic tree (Fig. 3d). At 65 d and beyond, YFP + fibers, presumably mossy fibers from YFP+ granule cells, densely innervated CA3. In addition, there was a significant increase in the proportion of recombined cells that expressed NeuN between $30 \mathrm{~d}$ and subsequent time points (Fig. $3 e, f)\left(F_{(2,8)}=41.4 ; p<0.0005\right)$. By $65 \mathrm{~d}$ after TAM, the percentage of YFP + cells that expressed NeuN reached a plateau with $\sim 50 \%$ of YFP + cells being neurons at 65 and $100 \mathrm{~d}$ (Fig. 3f). YFP+ astrocytes were rare (YFP+/S100B+/ $\mathrm{GFAP}+$ and astrocytic morphology), providing additional support that nestin-expressing stem cells give rise to neurons, not 
astrocytes. There was also a significant increase in YFP + cells that had a mature neuronal morphology in the outer GCL (oGCL) (Fig. $3 g)\left(F_{(4,42)}=2.9 ; p<0.05\right)$. However, the cells in the oGCL at all time points represented $<1 \%$ of all recombined cells, supporting that most maturing granule cells do not migrate from the SGZ into the oGCL (Kempermann et al., 2003). Together, these data underscore a link between nestin expression and neuronal fate.

\section{Discussion}

Multiple lines of evidence support our conclusion that TAM effectively drives recombination in nestin-expressing stem cells in the SVZ and SGZ during young adulthood. In nestin-CreER ${ }^{\mathrm{T} 2}$ / R26R-YFP mice, $96 \%$ of YFP + cells in the SGZ were nestin $+1 \mathrm{~d}$ after TAM, demonstrating that recombination occurs in nestinexpressing stem/progenitor cells. We also find at $12 \mathrm{~d}$ after TAM, $97 \%$ of stem-like cells (GFAP+/Sox $+/$ radial glial morphology) were recombined and that even at $100 \mathrm{~d}$ after TAM these cells were present. In addition, in vivo recombination led to YFP+ neurospheres in vitro and, as expected from labeled stem cells, maturing YFP+ progeny were increasingly evident after TAM. These data support that this mouse offers a potent tool for gene ablation studies in stem cells and their progeny.

The nestin-CreER ${ }^{\mathrm{T} 2} / \mathrm{R} 26 \mathrm{R}-\mathrm{YFP}$ mouse allows the first quantifiable assessment of the long-term contribution of nestinexpressing stem cells to adult neurogenesis in both the $\mathrm{OB}$ and dentate gyrus. For example, in the SGZ, we estimate the contribution of stem cells is $1 \%$, which is strikingly similar to previous estimates of the contribution of rapidly dividing cells (Doetsch and Hen, 2005) and validates that stem cells give rise to the rapidly dividing progenitor cells in the SGZ. In addition, we reveal intriguing dynamics of $\mathrm{YFP}+$ accumulation in the $\mathrm{OB}$ versus SGZ. YFP + cell density in the OB, which is dependent on the influx of YFP+ RMS neuroblasts and their surviving progeny, increased up to $100 \mathrm{~d}$ after TAM. We show the increase in density is attributable to the accumulation of maturing cells in the $\mathrm{OB}$ GCL and GL. This finding suggests the addition of new OB cells outpaces new cell turnover and might be expected because the volume of the murine $\mathrm{OB}$ increases in the first 2 years of life (Mirich et al., 2002). In contrast to the cell accumulation in the $\mathrm{OB}$, the number of YFP + cells in the SGZ reached a plateau $30 \mathrm{~d}$ after TAM. We were surprised to find a plateau in the number of $\mathrm{YFP}+$ neurons, because we expected an increase based on BrdUlabeling survival studies (Dayer et al., 2003; Kempermann et al., 2003). What could explain the steady state of YFP + cell number in the SGZ? One possibility is that the proportion of stem, precursor, and/or immature cells decreases with age (Rao et al., 2006; Hattiangady and Shetty, 2007). However, the presence of YFP+ radial glial cells $100 \mathrm{~d}$ after TAM and the steady state of the diverse population of recombined cells suggest that, over time, there is not an exhaustion of recombined stem cells. A second possibility is that analysis of longer times after TAM would reveal an eventual reduction in precursor number or activity, leading to a corresponding increase in the proportion of mature neurons. A third possibility is that the YFP transgene is silenced over time, leading to an underestimation of YFP+ cell number in the SGZ and producing the plateau seen $65-100 \mathrm{~d}$ after TAM. Although this is important to evaluate directly, this possibility is not supported by the increase in YFP+ cell number in the OB in our mouse, the similar steady-state dynamics seen in the SGZ of another transgenic mouse with an astrocyte-related gene driver of recombination (GLAST::CreER ${ }^{\mathrm{T} 2}$ ) (Ninkovic et al., 2007), and the general robustness of genes in the rosa locus. These and other possibilities are important to consider in the ongoing and necessary evaluation of the hypothesis that stem cells and their progeny achieve homeostasis in the adult mouse SGZ.

In addition to revealing the distinct accumulation dynamics in the SVZ and SGZ, our data also address the role of nestinexpressing cells in adult neurogenesis: most progeny of nestinexpressing YFP + cells are fated to become neurons. These data are in agreement with links between nestin expression and a specific lineage in many non-neuronal and oncogenic stem cells (Wiese et al., 2004). However, they are in contrast to the multilineage role for nestin in the embryo (Beech et al., 2004; Yu et al., 2005; Carlen et al., 2006; Imayoshi et al., 2006; Kuo et al., 2006; Burns et al., 2007), most notably in our nestin-CreER ${ }^{\mathrm{T} 2} / \mathrm{R} 26 \mathrm{R}-$ YFP mouse (Battiste et al., 2007). This underscores the importance of the permissive neurogenic microenvironment in determining the ultimate phenotypic fate of the progeny of nestinexpressing cells.

We show that nestin expression can ultimately result in neuronal, but not astrocytic, progeny. It is striking that inducible mouse models using astrocyte-related gene drivers [GFAP, GLAST (Garcia et al., 2004; Mori et al., 2006; Ninkovic et al., 2007)] drive expression in astrocytes throughout the brain, yet also give rise to neurons in the OB and SGZ. Interestingly, type 1 radial glial cells in the SGZ have recently been divided into categories of GFAP +/nestin - and GFAP +/nestin + (Kempermann et al., 2004; Seki et al., 2007). Thus, the ability of our nestin$\mathrm{CreER}^{\mathrm{T} 2} / \mathrm{R} 26 \mathrm{R}-\mathrm{YFP}$ mouse to generate YFP+ neurons in the OB and SGZ urges research on factors that guide a GFAP+ or GLAST + cell to become nestin +, to provide the much-needed information on neuronal fate restriction in the adult brain.

The nestin-CreER ${ }^{\mathrm{T} 2}$ mouse will clearly be useful in gene deletion or progenitor ablation studies. Although elegant, viralmediated Cre manipulation does not allow quantification of labeled cells along the longitudinal axis of the SGZ because of limited viral diffusion and often variability in titer between viral preparations (van Praag et al., 2002). Our nestin-CreER ${ }^{\mathrm{T} 2}$ mouse is extremely consistent between litters, emphasizing its usefulness for gene ablation studies. Similarly, it can be used to inducibly drive cell death of neural stem cells in the adult brain, offering an alternative to the current progenitor ablation strategies (e.g., Garcia et al., 2004). Because the nestin-CreER ${ }^{\mathrm{T} 2}$ mouse is inducible, it may also allow for future comparison of the present findings in young adulthood with neurogenesis in older mice, because the dynamics of neurogenesis may shift with age.

In conclusion, our data provide novel insights into the dynamic contribution of stem cells and their progeny to $\mathrm{OB}$ and dentate gyrus neurogenesis. The data strongly implicate that nestin expression is coincident with neuronal fate restriction. Furthermore, the quantification of the cellular and temporal specificity in the adult SVZ and SGZ validates this model as a valuable tool to guide future research identifying the contribution of stem cells and adult neurogenesis to neural circuitry and function.

\section{References}

Abusaad I, MacKay D, Zhao J, Stanford P, Collier DA, Everall IP (1999) Stereological estimation of the total number of neurons in the murine hippocampus using the optical disector. J Comp Neurol 408:560-566.

Battiste J, Helms AW, Kim EJ, Savage TK, Lagace DC, Mandyam CD, Eisch AJ, Miyoshi G, Johnson JE (2007) Ascll defines sequentially generated lineage-restricted neuronal and oligodendrocyte precursor cells in the spinal cord. Development 134:285-293.

Beech RD, Cleary MA, Treloar HB, Eisch AJ, Harrist AV, Zhong W, Greer CA, Duman RS, Picciotto MR (2004) Nestin promoter/enhancer directs 
transgene expression to precursors of adult generated periglomerular neurons. J Comp Neurol 475:128-141.

Brown JP, Couillard-Despres S, Cooper-Kuhn CM, Winkler J, Aigner L, Kuhn HG (2003) Transient expression of doublecortin during adult neurogenesis. J Comp Neurol 467:1-10.

Burns KA, Ayoub AE, Breunig JJ, Adhami F, Weng WL, Colbert MC, Rakic P, Kuan CY (2007) Nestin-CreER mice reveal DNA synthesis by nonapoptotic neurons following cerebral ischemia-hypoxia. Cereb Cortex 17:2585-2592.

Carlen M, Meletis K, Barnabe-Heider F, Frisen J (2006) Genetic visualization of neurogenesis. Exp Cell Res 312:2851-2859.

Dayer AG, Ford AA, Cleaver KM, Yassaee M, Cameron HA (2003) Shortterm and long-term survival of new neurons in the rat dentate gyrus. J Comp Neurol 460:563-572.

Doetsch F, Hen R (2005) Young and excitable: the function of new neurons in the adult mammalian brain. Curr Opin Neurobiol 15:121-128.

Doetsch F, Caille I, Lim DA, Garcia-Verdugo JM, Alvarez-Buylla A (1999) Subventricular zone astrocytes are neural stem cells in the adult mammalian brain. Cell 97:703-716.

Donovan MH, Yazdani U, Norris RD, Games D, German DC, Eisch AJ (2006) Decreased adult hippocampal neurogenesis in the PDAPP mouse model of Alzheimer's disease. J Comp Neurol 495:70-83.

Forni PE, Scuoppo C, Imayoshi I, Taulli R, Dastru W, Sala V, Betz UA, Muzzi P, Martinuzzi D, Vercelli AE, Kageyama R, Ponzetto C (2006) High levels of Cre expression in neuronal progenitors cause defects in brain development leading to microencephaly and hydrocephaly. J Neurosci 26:9593-9602.

Ganat YM, Silbereis J, Cave C, Ngu H, Anderson GM, Ohkubo Y, Ment LR, Vaccarino FM (2006) Early postnatal astroglial cells produce multilineage precursors and neural stem cells in vivo. J Neurosci 26:8609-8621.

Garcia AD, Doan NB, Imura T, Bush TG, Sofroniew MV (2004) GFAPexpressing progenitors are the principal source of constitutive neurogenesis in adult mouse forebrain. Nat Neurosci 7:1233-1241.

Graham V, Khudyakov J, Ellis P, Pevny L (2003) SOX2 functions to maintain neural progenitor identity. Neuron 39:749-765.

Harburg GC, Hall FS, Harrist AV, Sora I, Uhl GR, Eisch AJ (2007) Knockout of the mu opioid receptor enhances the survival of adult-generated hippocampal granule cell neurons. Neuroscience 144:77-87.

Hattiangady B, Shetty AK (2007) Aging does not alter the number or phenotype of putative stem/progenitor cells in the neurogenic region of the hippocampus. Neurobiol Aging, in press.

Imayoshi I, Ohtsuka T, Metzger D, Chambon P, Kageyama R (2006) Temporal regulation of Cre recombinase activity in neural stem cells. Genesis 44:233-238.

Indra AK, Warot X, Brocard J, Bornert JM, Xiao JH, Chambon P, Metzger D (1999) Temporally-controlled site-specific mutagenesis in the basal layer of the epidermis: comparison of the recombinase activity of the tamoxifen-inducible Cre-ER(T) and Cre-ER(T2) recombinases. Nucleic Acids Res 27:4324-4327.

Kempermann G, Gast D, Kronenberg G, Yamaguchi M, Gage FH (2003) Early determination and long-term persistence of adult-generated new neurons in the hippocampus of mice. Development 130:391-399.

Kempermann G, Jessberger S, Steiner B, Kronenberg G (2004) Milestones of neuronal development in the adult hippocampus. Trends Neurosci $27: 447-452$.

Komitova M, Eriksson PS (2004) Sox-2 is expressed by neural progenitors and astroglia in the adult rat brain. Neurosci Lett 369:24-27.

Kronenberg G, Reuter K, Steiner B, Brandt MD, Jessberger S, Yamaguchi M, Kempermann G (2003) Subpopulations of proliferating cells of the adult hippocampus respond differently to physiologic neurogenic stimuli. J Comp Neurol 467:455-463.

Kuo CT, Mirzadeh Z, Soriano-Navarro M, Rasin M, Wang D, Shen J, Sestan N, Garcia-Verdugo J, Alvarez-Buylla A, Jan LY, Jan YN (2006) Postnatal deletion of Numb/Numblike reveals repair and remodeling capacity in the subventricular neurogenic niche. Cell 127:1253-1264.

Lemasson M, Saghatelyan A, Olivo-Marin JC, Lledo PM (2005) Neonatal and adult neurogenesis provide two distinct populations of newborn neurons to the mouse olfactory bulb. J Neurosci 25:6816-6825.

Lois C, Alvarez-Buylla A (1994) Long-distance neuronal migration in the adult mammalian brain. Science 264:1145-1148.

Mandairon N, Sacquet J, Jourdan F, Didier A (2006) Long-term fate and distribution of newborn cells in the adult mouse olfactory bulb: influences of olfactory deprivation. Neuroscience 141:443-451.

Mandyam CD, Norris RD, Eisch AJ (2004) Chronic morphine induces premature mitosis of proliferating cells in the adult mouse subgranular zone. J Neurosci Res 76:783-794.

Mandyam CD, Harburg GC, Eisch AJ (2007) Determination of key aspects of precursor cell proliferation, cell cycle length and kinetics in the adult mouse subgranular zone. Neuroscience 146:108-122.

Merson TD, Dixon MP, Collin C, Rietze RL, Bartlett PF, Thomas T, Voss AK (2006) The transcriptional coactivator Querkopf controls adult neurogenesis. J Neurosci 26:11359-11370.

Ming GL, Song H (2005) Adult neurogenesis in the mammalian central nervous system. Annu Rev Neurosci 28:223-250.

Mirich JM, Williams NC, Berlau DJ, Brunjes PC (2002) Comparative study of aging in the mouse olfactory bulb. J Comp Neurol 454:361-372.

Mori T, Tanaka K, Buffo A, Wurst W, Kuhn R, Gotz M (2006) Inducible gene deletion in astroglia and radial glia-a valuable tool for functional and lineage analysis. Glia 54:21-34.

Ninkovic J, Mori T, Gotz M (2007) Distinct modes of neuron addition in adult mouse neurogenesis. J Neurosci 27:10906-10911.

Parrish-Aungst S, Shipley MT, Erdelyi F, Szabo G, Puche AC (2007) Quantitative analysis of neuronal diversity in the mouse olfactory bulb. J Comp Neurol 501:825-836.

Pevny L, Rao MS (2003) The stem-cell menagerie. Trends Neurosci 26:351-359.

Rao MS, Hattiangady B, Shetty AK (2006) The window and mechanisms of major age-related decline in the production of new neurons within the dentate gyrus of the hippocampus. Aging Cell 5:545-558.

Seki T, Namba T, Mochizuki H, Onodera M (2007) Clustering, migration, and neurite formation of neural precursor cells in the adult rat hippocampus. J Comp Neurol 502:275-290.

Seri B, Garcia-Verdugo JM, McEwen BS, Alvarez-Buylla A (2001) Astrocytes give rise to new neurons in the adult mammalian hippocampus. J Neurosci 21:7153-7160.

Seri B, Garcia-Verdugo JM, Collado-Morente L, McEwen BS, Alvarez-Buylla A (2004) Cell types, lineage, and architecture of the germinal zone in the adult dentate gyrus. J Comp Neurol 478:359-378.

Soriano P (1999) Generalized lacZ expression with the ROSA26 Cre reporter strain. Nat Genet 21:70-71.

van Praag H, Schinder AF, Christie BR, Toni N, Palmer TD, Gage FH (2002) Functional neurogenesis in the adult hippocampus. Nature 415:1030-1034.

Wiese C, Rolletschek A, Kania G, Blyszczuk P, Tarasov KV, Tarasova Y, Wersto RP, Boheler KR, Wobus AM (2004) Nestin expression-a property of multi-lineage progenitor cells? Cell Mol Life Sci 61:2510-2522.

Yamaguchi M, Saito H, Suzuki M, Mori K (2000) Visualization of neurogenesis in the central nervous system using nestin promoter-GFP transgenic mice. NeuroReport 11:1991-1996.

Yu TS, Dandekar M, Monteggia LM, Parada LF, Kernie SG (2005) Temporally regulated expression of Cre recombinase in neural stem cells. Genesis 41:147-153.

Zimmerman L, Parr B, Lendahl U, Cunningham M, McKay R, Gavin B, Mann J, Vassileva G, McMahon A (1994) Independent regulatory elements in the nestin gene direct transgene expression to neural stem cells or muscle precursors. Neuron 12:11-24. 